\title{
Magnetoresistor Device
}

National Cancer Institute

\section{Source}

National Cancer Institute. Magnetoresistor Device. NCI Thesaurus. Code C50042.

A variable resistor that can be controlled by a magnetic field. 